\title{
A thematic analysis of nursing students' end-of-life knowledge
}

\begin{abstract}
Background: Nursing Associations recommend that undergraduate nursing programs integrate end-of-life content throughout their nursing curricula to address the needs of those requiring such care.

Objective: To determine the extent of nursing students' knowledge about end-of-life care in the final year of an undergraduate nursing program in Ontario, Canada.

Method: The content of reflective exercises written by 24 nursing students enrolled in an end-of-life elective were thematically analyzed, both at the beginning and end of a 12week course.

Results: Results indicate that undergraduate nursing students' end-of-life knowledge and experiences vary greatly. The overarching theme Duty of Care indicated that the students were motivated to take the course to fulfill a sense of professional responsibility. The sub-themes Assumptions and Experience (subdivided as Limited, Personal, and Professional) depicted students' initial and variable understanding of end-of-life care. Under the theme of Transferable Skills, the students' range of knowledge and the competencies they gained from their clinical placements and the course were illustrated.

Conclusion: The study is expected to aid in curriculum review of a university's undergraduate nursing program.
\end{abstract}

\section{Author:}

Susanna Edwards RN, PhD

Associate Professor

Daphne Cockwell School of Nursing

Ryerson University

edwardss@ryerson.ca 


\section{A thematic analysis of nursing students' end-of-life knowledge}

\section{Background}

The Registered Nurses Association of Ontario (RNAO, 2011) and the Canadian Association of Schools of Nursing (CASN, 2011) have called for palliative or end-of-life care to be threaded throughout undergraduate nursing programs rather than added to the curriculum as an elective course. However, incorporating end-of-life content throughout the curriculum of an undergraduate nursing degree program may be difficult due to the competing demands of other course content (Kantor, 2010; Wilson, Goodwin, and Hewitt, 2011). Periodic reviews of a curriculum offer a good opportunity for nursing faculty to assess a program's learning goals and objectives in relation to societal needs (Iwasiw, and Goldenberg, 2015; Rosy, 2015). Social forces such as demographic change, technology, globalization, and economic or political issues may warrant changes in nursing school curricula (Soto, 2015). Statistics about impending increases in the number of seniors, the global cohort that requires end-of-life care, indicate that the time has come to alter the curricula of nursing programs (CHPC, 2013; Cohen, and Deliens, 2012; Langille, 2013). The results of this study are expected to assist with the curriculum review of a nursing program in a university in Ontario, Canada.

\section{Method}

A thematic content analysis was conducted on the texts from two reflective exercises written by 24 students enrolled in an end-of-life elective course in the final year of their nursing program at a university in Ontario, Canada. This method is related to phenomenology, a philosophy that focuses on one's lived experience and has been effective in research that explores self-assessment of nursing practice (Fereday, and 
Muir-Cochrane, 2006). As a qualitative research method thematic analysis examines themes within textual data. Coding, the primary process for the development of themes, allows the investigator to extract meaning from the data that captures the participants' experiences (Greg, MacQueen, and Namey, 2012). Rigor was maintained throughout the study by ensuring that its design and implementation was congruent with the methodological literature (Mayan, 2001; Morse, Barrett Mayan, Olson, and Spiers, 2002).

\section{Recruitment}

At the end of the school term after all assignments had been graded, two e-mails two weeks apart - were sent from the study's online site to 48 students who had completed a 12-week End-of-Life Care elective course for undergraduates and postdiploma nurses. The web site contained three demographic questions (age, gender, and type of nursing program), and a consent form seeking student permission to analyze the two reflective exercises they had written as part of the course. The students were informed that participation in the study was unrelated to their grades, and advised that while they may not benefit directly from the research, the results would assist the investigator to improve future end-of-life content in the undergraduate nursing program. A letter of support from the School of Nursing's Director and Associate Directors was submitted with the Research Ethics Board application, and approval to conduct the study was subsequently received.

\section{Participants}

Twenty female and four male nursing students with an age range from 21 to 43 years participated in the study. Twenty-two students were enrolled in the four-year 
undergraduate nursing program and two were in the two-year post-diploma undergraduate program.

\section{Reflective Exercises}

The content and design of the End-of-Life elective course is underpinned by the entry to practice competencies for end-of-life care that are outlined by the Canadian Association of Schools of Nursing (CASN, 2011). Students are encouraged to engage in reflective thought about palliative or end-of-life care to guide and develop their understanding of the issues pertaining to the competencies (CASN, 2011; Ferrell, 2016). The reflective exercises - written at the beginning and end of the course - were, therefore, designed in an open-ended format to tap into the students' thoughts and experiences. The students were advised to write, 'what you know' based on their lived experiences rather than be concerned about 'the right answer', and the grading focus was on the thoroughness of their responses rather than the content.

The questions enquired about: motivation to take the course, knowledge about end-of-life care prior to taking the course, employment plans upon graduation, how the course content might be applied in a future workplace, and whether taking an elective course in the final year of the nursing program is sufficient to be competent in end-of-life care.

\section{Results}

Each student contributed two exercises for analysis; therefore, 48 exercises consisting of approximately 4 to 5 pages each were thematically analyzed. The original texts had been written in longhand within a proscribed time period during class; these were transcribed into a computer word document, grouped by question, and then coded. 


\section{Themes}

The overarching theme Duty of Care indicated that students were motivated to take the course due to a sense of professional responsibility. The sub-themes of Assumptions and Experience (subdivided as Limited, Personal, and Professional) depicted students' understanding of end-of-life care at the beginning and during the course; their comments on Societal Issues reflected an increased awareness of the complex legal and ethical aspects involved in contemporary situations; and under the theme of Transferable Skills, the students illustrated the knowledge and competencies they gained from their clinical placements and the end-of-life course.

\section{Duty of Care}

The overarching Duty of Care theme highlighted the students' sense of responsibility as nurses to care for those who are dying. The students felt that, whatever the type of their future employment, end-of-life care was a necessary component of their nursing care. As one student stated, "we know that in nursing, end of life is unavoidable, as nurses we deal with dying people no matter where we work and where we are placed". Students also indicated that it was necessary to have a basic understanding of this aspect of nursing to be able to know what their future clients would face and to be able to assist them to retain dignity and meaning in their final days.

\section{Assumptions}

The students' thoughts about end-of-life care prior to taking the course revealed their initial impressions. Some saw the dying as "already dead, not alive people". By the end of the course, some students admitted that they had undervalued the significance of 
end-of-life care. Most felt that this was not a popular area for new nurses "because there is a lack of awareness of end-of-life issues". Some students shied away from the topic because it would not be 'easy', and some comments reflected the general societal denial of death: "Death and dying is a far away concept, something that I do not have to consider yet until I am much older".

\section{Experience}

Textual content that addressed the students' rationale for taking the course was categorized under the Experience sub-theme, which was further sub-divided into Limited, Personal, and Professional themes that revealed the students' range of experiences with dying and related these to their developing awareness of the challenges involved as health professionals.

\section{Limited}

Some students did not have an opportunity during their nursing program to take care of someone who was dying, and wondered what they would need to know and what they should say to such clients. Others who had had some clinical experience in a hospice or a long-term care setting felt unprepared and ill-equipped with knowledge and experience when dealing with dying clients. One student said, "I knew there was palliative care and hospices but did not know what happens there and why they are important". Another revealed that a nurse had referred to their nursing care as being 'palliative' but did not fully understand that comment until the first day of the end-of-life class. 


\section{Personal}

Students who related a death experience derived from among their own loved ones said they had felt unsupported and adrift due to a lack of coping strategies. Having had to deal with the death of a parent, grandparent, or good friend prompted some students' existential questioning about the death trajectory, death process, and grief and bereavement. They were forced to face their own mortality, not having considered dying as something that could happen at a young age. Others wished to build upon their personal experiences to be able to assist clients facing death and, in the words of one student, "to gain an understanding on where I stand as a health care professional and as a human being". Those with a family member diagnosed with Alzheimer's disease found it challenging to balance work and caregiving, which often eclipsed other more enjoyable activities that they no longer had time to do. Personal experiences also prompted some favourable conclusions about the health care system, as this quote reveals: "My family has not been a stranger to death, both abrupt quick deaths and long trajectories drawn out over several years. I have also been witness to the impact that quality end-of-life care has on a patient and their support system".

\section{Professional}

A few students had positive and rewarding professional experiences, one student referred to "working in a wonderful hospice, which served as the foundation of my knowledge about end-of-life care". An important aspect of such experiences was the constant communication between clients and families, health care professionals, and other support workers about the care that the clients and their families were receiving. 
While other students had faced situations in which they felt uncertain about how to assist struggling families or patients. Particularly challenging was knowing how to support the families of children that were at the end stages of their illness. Those who had worked in a continuing care unit noted that more and more patients required palliative care and a student with experience in an Intensive Care unit observed, "it looked like continuous fighting for life, regardless of patient choice".

\section{Societal Issues}

The sub-theme Societal Issues depicted students' understanding of a range of social and ethical issues that affect end-of-life care. The students revealed an awareness that a growing number of seniors will soon require end-of-life care and may not have their wishes satisfied, such as the ability to die in their home rather than in a hospital setting. The students also referred to the legal and ethical aspects of advance directives and medical assistance in dying, which may not be fully understood by their patients; and they hoped that, as one student stated, "This course would bring insight on how end-oflife care works in Canada". Concerns about equity in health services were noted: "In Canada there is unequal access to programs in palliative care - reasons for this include geography, limited resources, health care team training, education and skill - this means that patients will be facing many barriers".

\section{Transferable Skills}

An aspect of the course that surprised students was the applicability of many endof-life concepts to other areas of nursing. All references to the knowledge and competencies that students gained from their clinical placements throughout the duration 
of their undergraduate nursing program, including the end-of-life course taken in the last semester of their program, were combined under the theme of Transferable Skills. These were distinguished by learning source: clinical placements or end-of-life course.

\section{Knowledge from clinical placements}

Many students lacked a basic knowledge of end-of-life concepts when they began clinical placements in long-term care, hospices, or palliative care units. Their experiences in these placements increased their familiarity with these concepts and with treatments that differed from their previous clinical experiences in acute care settings. One student wrote about her more nuanced understanding of euthanasia: "The difference between euthanasia and palliative sedation stood out for me during my clinical placement at a hospice. The huge doses of pain medication ... scared me as I knew that I could hasten death ... but if the intent is to alleviate pain and not end life then it is not considered euthanasia". Students placed in long-term care homes with clients who had dementia expressed concerns about the ability of this vulnerable population to receive holistic care, and planned to be aware of these issues in the future. Others gained a better understanding of the importance of respecting a client's right to choose or not choose treatment. The basic tenets of palliative care were also clarified for students; one student expressed it thus, "I learned from my clinical rotation that end-of-life care does not only involve caring for the patients who are critically ill or nearing their death but also support for the family or carers providing care to their loved ones who are approaching death". 


\section{Knowledge from the course}

Students indicated that the end-of-life elective course gave them a full overview of the care needs of the terminally ill, as this comment shows: "I had no idea what I needed to know to care for palliative patients. It is more than death, it's quality of life, it's the patient's thoughts, feelings, and wishes - that is why I think I not only gained knowledge ... but I will also do my best to provide patients with knowledge". Students who had initially expressed discomfort about communicating with the dying realized at the conclusion of the course that "I always felt that I had to do something but now realize that being present and actively listening is the most therapeutic activity I can do". The end-of-life course also considered the idea of death within the context of modern society and the current health care system, which can take a combative stance to dying: "I understand that today's consumer culture often denies death, and health providers often pursue questionably effective, burdensome therapies rather than take comfort in the fact that life may be coming to an end".

The final question in the second reflective exercise at the end of the course asked students to rate their competency in end-of-life care after taking the course; it required a simple 'yes, no, or maybe' answer: 13 students responded 'no'; 10 responded 'yes' and 1 responded 'maybe'. Since they were not asked to explain or elaborate on their answer, it is difficult to interpret this data, but it raises further questions that might guide future research. For example, is more clinical experience required to bolster student confidence? It is also worth noting that the students who were not enrolled in the study responded similarly to those who were. 


\section{Discussion}

The purpose of this study was to determine what students taking an elective course in the final year of their undergraduate nursing program in Ontario, Canada knew about palliative or end-of-life care prior to graduation from the program. The grading component of the reflective exercises may have influenced student responses to the questions. As indicated previously however, students were informed that the content of their reflections would not be graded, the main criteria for grading was that their responses were thorough, meaning that they fulfilled the requirement of 4 to 5 pages written in a scholarly manner. As well, the time limit for the exercises was set at one hour to deter overthinking of the questions and to promote genuine responses. It should be noted that the students were not new to this type of written exercise since these reflections were built into the school of nursing's curriculum from the beginning of the program. Such exercises are intended to "develop critical and reflexive thinking and attitudes in nursing” (Barbosa, \& Pereira, 2015, p. 1860).

The majority of students who enrolled in the end-of-life course and who participated in the study intended to work in an area such as long-term care, oncology, community health, or general surgery where knowledge from the end-of-life course would be helpful. Some students had previous experience with palliative care or familiarity with end-of-life concepts; others took the course to gain experience in an area of nursing that was unfamiliar to them. Those with previous experience said the course addressed aspects that they had wondered about. Those with no experience felt that they now had a beginning knowledge about end-of-life concepts. Hence, their answers - as noted above - to the final question about whether an end-of-life elective course was 
sufficient for developing proficiency in end-of-life care received a mixed review wherein only half the students felt fully confident to care for the dying.

The demand for palliative or end-of-life care in Canada and other countries will undoubtedly grow in the coming decades as the number of seniors is expected to increase (Fowler, \& Hammer, 2013). It is, therefore, incumbent upon faculty in schools of nursing to respond to these societal trends and alter the curricula accordingly (Iwasiw, \& Goldenberg, 2015; Rosy, 2015; Soto, 2015). The faculty of an undergraduate nursing program in Ontario, Canada have, therefore, embarked upon a three-year curriculum review process - the results of this study are expected to assist in that review.

\section{Conclusion}

The results of this study illustrate that nursing students' personal, clinical, and knowledge about end-of-life care over the course of their undergraduate-nursing program is variable. The students' reflections, suggests that they desire more education and training on this topic than is available when it is only offered as an elective course taken in the final year of their nursing program. In a North American society that largely denies the reality of death, nursing students require the opportunity to focus their learning about the full experience of a natural trajectory of life through to its end. To ensure that all nursing students have a basic understanding of end-of-life care it is imperative that the topic be introduced to all students in a consistent manner throughout their undergraduate program and that they have sufficient practice knowledge to assist our most vulnerable patients at the end of their lives.

Acknowledgements: The author is grateful to the nursing students who so eloquently shared their experiences in end-of-life care. 


\section{References}

Barbosa, L. R., \& Pereira, L. L. (2015). Nursing education in a curriculum oriented to competence: A systematic review. Creative Education, 6, 1860-1866, (p.1860).

Canadian Association of Schools of Nursing (CASN). (2011). Palliative and end-of-life care: entry to practice competencies and indicators for Registered Nurses. Ottawa, Ontario: Author.

Canadian Hospice Palliative Care Association (CHPC). (2013). Fact sheet: Hospice Palliative care in Canada. Ottawa, Ontario: Author.

Cohen, J., \& Deliens, L. (2012). A public health perspective on end of life care. Oxford Scholarship Online: DOI:10.1093/acprof:oso/9780199599400.001.0001

Ferrell, B., Malloy, P., Mazanec, P., \& Virani, R. (2016). CARES: AACN's new competencies and recommendations for educating undergraduate nursing students to improve palliative care. Journal of Professional Nursing, 32(5), 327-333.

Fereday, J., \& Muir-Cochrane, E. (2006). Demonstrating rigor using thematic analysis: A hybrid approach of inductive and deductive coding and theme development. International Journal of Qualitative Methods, 5 (1).

Fowler, R., \& Hammer, M. (2013). End-of-life care in Canada. Clinical and Investigative Medicine, 36 (3).

Greg, G., MacQueen, K. M., \& Namey, E. E. (2012). Applied thematic analysis. Thousand Oaks, CA: Sage. 
Iwasiw, C. L. \& Goldenberg, D. (2015). Curriculum development in nursing education. Burlington, MA: Jones \& Bartlett Learning.

Kantor, S. A. (2010). Pedagogical change in nursing education: One instructor's experience. Journal of Nursing Education, 49(7), 414-117.

Langille, J. (2013). Rights of passage: A new approach to palliative care. Canadian Nurse, 109 (9), 26-31.

Mayan, M. J. (2001). An introduction to qualitative methods. Edmonton, Alberta, Canada: Qualitative Press.

Morse, J. M., Barrett, M., Mayan, M., Olson, K., \& Spiers, J. (2002). Verification strategies for establishing reliability and validity in qualitative research. International Journal of Qualitative Methods, 1(2), 1-19.

Registered Nurses Association of Ontario (RNAO). (2011). End-of-life care during the last days and hours. Toronto, Ontario, Canada: Author.

Rosy, M. M. (2015). Research in curriculum development. Asian Journal of Nursing Education and Research ,5(3), 431- 436.

Soto, T. S. (2015). An analysis of curriculum. Theory and Practice in Language Studies, $5(6), 1129-1139$.

Wilson, D. M., Goodwin, B. L., \& Hewitt, J. A. (2011). An examination of palliative or end-of-life care education in introductory nursing programs across Canada. Nursing Research and Practice, 1, 1-5. 